\title{
Trends of Rotavirus Diarrhea in Hospitalized Children in Yogyakarta Year 2013-2015
}

\author{
Nenny Sri Mulyani ${ }^{1,3}$, Dian Anggraini ${ }^{2}$, Retno Palupi-Baroto ${ }^{1,3}$, Asal Wahyuni Erlin \\ Mulyadi i,4, Rizki Anindita ${ }^{3}$, Yati Soenarto ${ }^{1,3}$ \\ ${ }^{1}$ Department of Child Health Faculty of Medicine Universitas Gadjah Mada / Dr. Sardjito \\ Hospital Yogyakarta Indonesia. ${ }^{2}$ Department of Child Health Wates District Hospital \\ Kulonprogo Yogyakarta, Indonesia, ${ }^{3}$ Pediatric Research Office, Department of Child \\ Health Faculty of Medicine Universitas Gadjah Mada / Dr. Sardjito Hospital Yogyakarta \\ Indonesia, ${ }^{4}$ Department of Public Administration Faculty of Social and Political Sciences \\ Universitas Sebelas Maret Surakarta Indonesia
}

DOI: http://dx.doi.org/10.19106/JMedScieSup005001201807

\section{ABSTRACT}

Diarrhea, together with pneumonia, is accountable for $25 \%$ death of children under five globally (IVAC, 2017). In Indonesia, diarrhea is also among the top ten diseases of cause of death in children under five (WHO, 2015). Rotavirus diarrhea is responsible for $60 \%$ in 2006 (Soenarto et al, 2009) of children diarrhea in Indonesia. Rotavirus vaccine in Indonesia was introduced commercially in 2011, nonetheless its use was reportedly low. Despite the declining rate of rotavirus incidence, surveillance is important to show the burden of rotavirus diarrhea in children. Thus, this study aims to describe the incidence of rotavirus diarrhea in hospitalized children under five in Yogyakarta province. The trend of rotavirus diarrhea in children under 5 years increased over the years' period. The rotavirus diarrhea mostly presented with dehydration, thus rotavirus diarrhea remains as significant contributor to hospitalized children with diarrhea. This shows an evidence that the burden of rotavirus diarrhea in children under 5 years remains prominent.

Keywords: rotavirus diarrhea, vaccine, children under five, Indonesia

*corresponding author: rotavirus_yogyakarta@yahoo.com 